\title{
La seguridad humana de los familiares de víctimas de desaparición forzada en México*
}

\author{
The human security of the relatives of victims \\ of enforced disappearance in Mexico
}

\author{
Alejandra Flores Martínez \\ Universidad Autónoma del Estado de México \\ licale_23@hotmail.com \\ Norma I. González Arratia \\ Universidad Autónoma del Estado de México \\ nigalf@yahoo.com.mx
}

Sumario: Introducción. 1. Metodología cualitativa. 2. Desaparición forzada en la actualidad mexicana. 3. La seguridad humana y los modelos teóricos que la intentan explicar. 4. La seguridad emocional: parte del núcleo de la seguridad humana. 5. Posible construcción de la seguridad humana de los familiares de personas desaparecidas forzadas: exposición de datos y análisis de resultados. 6. Conclusiones. 7. Referencias.

Resumen: Esta investigación se centra en analizar el fenómeno de las desapariciones forzadas dentro del marco teórico de la seguridad humana. Desde el enfoque epistemológico de este estudio es urgente construir una seguridad desde y para el ser humano; esto se traduce en determinarla a partir de los individuos sumergidos en sus pensamientos, emociones y en su ambiente cultural-social. Para ello, se ha desarrollado una investigación cualitativa con el objetivo de conocer cómo enfrenta la familia la desaparición de uno de sus miembros a través de una entrevista grupal-semiestructurada y una entrevista estructurada abierta. Los resultados reportan que cada participante reacciona con diferentes conductas y emociones ante la situación, pero la mayoría busca una red de apoyo para enfrentar la adversidad.

* Cómo citar: Flores Martínez, Alejandra y González Arratia, Norma I. 2019. "La seguridad humana de los familiares de víctimas de desaparición forzada en México". Deusto Journal of Human Rights, 4: 177-202. http://dx.doi.org/18543/djhr-42019pp177-202 
Palabras clave: desaparición forzada, seguridad humana, derechos humanos, seguridad emocional, bienestar social.

Abstract: This research focuses on the analysis of the phenomenon of enforced disappearances within the theoretical framework of human security. From the epistemological premises of this study, it seems urgent to develop a security framework from and for the human being. And this is done here from the individuals immersed in their thoughts, emotions and in their socialcultural environment. For this, a qualitative research has been carried out with the aim of learning how the family faces the disappearance of one of its members through a semi-structured focal group interview and an open structured interview. The results reveal that each participant reacts differently in terms of emotions and behaviors, but most of them seek a support network to face adversity.

Keywords: enforced disappearance, human security, human rights, emotional security, social welfare. 


\section{Introducción}

Una de las tareas prioritarias para todo Estado es la seguridad de sus habitantes. Cualquier medida de seguridad no es válida sin antes evaluarla bajo los elementos que legitiman la existencia de un Estado Constitucional, pues estas medidas legales y políticas públicas no deben trasgredir los derechos humanos.

Conforme a la visión formal de un Estado Constitucional, su legitimidad se haya en garantizar los derechos fundamentales ${ }^{1}$. No obstante, como explica Feierstein $(2017,45)$ la conformación de los Estados-nación modernos, desde las experiencias europeas de los siglos XV a XIX hasta las experiencias americanas durante el siglo XIX, o africanas durante el siglo $x \mathrm{x}$, exigió, en la mayoría de los casos, una reformulación de las relaciones sociales en el territorio elegido para el surgimiento de dicho Estado que, en general, requirió de prácticas sociales genocidas como modalidad operatoria. Entonces, existe una contradicción entre la visión formal y material de la construcción de los Estados-nación, ya que su implantación trajo consigo el aniquilamiento de los individuos considerados diferentes. Por tanto, la edificación del Estado moderno nació con la práctica de exterminio bajo la premisa de la "unidad homogénea de la población" (Jellinek 1911, 313). Los sucesos de exterminio, según Bauman (1997), son calificados bajo la hipótesis de modernidad exacerbada y las entidades, objeto de desaparición, son el producto más refinado del proyecto civilizatorio. Es decir; por un lado, este proyecto de modernidad hace visible a los individuos con carta plena de ciudadanía, racionales e ilustrados; por otro lado, desaparece a los individuos que considera sucios, diferentes o indeseables (Gatti 2011, 54).

En el México actual las decisiones gubernamentales defienden una visión de política pública en materia de seguridad nacional focalizada en los enemigos de la soberanía de los Estados, y la seguridad pública en aspectos reactivos y preventivos frente a la comisión de delitos. Sin embargo, dichas políticas no detectan los umbrales de peligro que impiden vivir a las personas libres de miedo; es decir, no contribuyen a "desaparecer las amenazas críticas dominantes para el desarrollo de las personas" (Baena 2006, 31). En este tenor, surge la interrogante sobre si la seguridad al interior del Estado debe constreñirse a prevenir

1 Así es defendido desde el artículo 16 de la Declaración de los Derechos del Hombre y del Ciudadano de 1793, y diversos constitucionalistas clásicos y modernos lo defienden en igual sentido. Véase: Loewenstein (2018) y Smend (1985). 
y castigar al transgresor del orden penal o si esta seguridad requiere atender el desarrollo humano de forma integral.

Desde la postura teórica de este estudio se defiende que las condiciones que generan miedo no sólo provienen de delincuentes sino, en igual o mayor grado, de las consecuencias negativas de colocar a los militares en las calles, así como de las pocas posibilidades para el desarrollo del individuo dentro de una comunidad (falta de servicios de salud, desempleo, etc.).

La política de seguridad está diseñada para atacar a los enemigos del Estado; esto es cuestionable por mantener una concepción bélica apartada de generar condiciones de estabilidad y paz para los habitantes del territorio. Esta tesis basada en el poder y el orden conlleva a que si un individuo se revela contra las decisiones estatales será calificado como enemigo; por lo tanto, el derecho penal y la seguridad al interior del Estado se direccionan en eliminarlo. El problema de privilegiar el poder y el orden es que siempre tienen lugar a expensas de otras personas -y son, por tanto, potencialmente inestables- (Booth 2013, 107).

Desde la concepción de Günther (2003, 21 y ss.) existen dos tendencias opuestas que convergen en un solo contexto jurídico-penal: el Derecho Penal del Enemigo y el Derecho Penal del Ciudadano. Para este autor es posible que estas tendencias se superpongan, es decir, que se solapen aquellas conducentes a tratar al autor de un delito como persona, y aquellas otras dirigidas a tratarlo como fuente de peligro o como medio para intimidar a otros. Kant (2003) sostiene que el Derecho Penal del Ciudadano es el Derecho de todos; por consiguiente, el Derecho Penal del Enemigo es también de quienes están contra él, y frente a éste es sólo coacción física, hasta llegar a la guerra.

El error epistémico consiste en que la política de seguridad se diseña tomando al Estado como sujeto a proteger. Siguiendo la analogía de Booth $(2013,107)$, la seguridad está planeada para cuidar una casa (Estado) y se gasta mucho para ello, por lo que deja de lado a sus habitantes, justificando la desaparición legal o ilegal del enemigo. Para este autor "seguridad" significa la ausencia de amenazas, y sugiere una emancipación de los roles de poder y orden estatales, para que la gente - como individuos o grupos - dejen de lado aquellas limitaciones físicas y humanas que no se les permiten vivir con libertad. La guerra y la amenaza, junto con la pobreza, falta de educación, opresión política, entre otras, son algunas de estas limitaciones.

Seguridad y emancipación son dos caras de la misma moneda. La emancipación, no el poder o el orden, produce la verdadera seguridad; sin embargo, en el escenario actual se acude a la guerra para hacer 
frente a los supuestos enemigos, se le niega el estatus de persona al sujeto que no admite ser obligado por el Estado o ajustado al proyecto de modernidad. En términos de Kant (2003), la guerra, como política de seguridad, tiene un ingrediente importante: la militarización. En este tenor, al Estado no le interesa la protección de sus habitantes, ya que los expone a condiciones de vulnerabilidad en manos de delincuentes, policías y militares. Para Luigi Ferrajoli $(2010,45-46)$ el derecho penal del enemigo es una fórmula que introduce la lógica de la guerra en el derecho: cuando el derecho es la negación de la guerra y la guerra la negación del derecho.

Por ello, en este trabajo se cuestiona si resulta necesario abrigar una tesis teórica diferente que sostenga a la seguridad o, en términos de Booth (2013), emancipar la seguridad del rol del poder estatal. La seguridad podría diseñarse para lograr el desarrollo armónico de las personas a través de diferentes medidas jurídicas, políticas, económicas y sociales.

\section{Metodología cualitativa}

Al ser una investigación cualitativa, las vías de indagación son provisionales y el diseño nunca puede ser definitivo: la mayoría de las decisiones son tomadas a medida que se avanza en la investigación. Sabemos que el objeto, el hecho, se conquista y se define antes de comprobarlo (Bourdieu et al. 2002); por ello, el enfoque cualitativo no es producido a partir de ninguna teoría formal, ya que éstas se formulan únicamente como guía de actuación y búsqueda, sin estar demasiado definidas (Penalva et al. 2015, 19).

Esta pesquisa tiene como propósito analizar el fenómeno de las desapariciones forzadas desde la experiencia de los familiares, ya que esta vivencia para algunos expertos puede traducirse en una "desestructuración de la identidad individual y comunitaria" (Rangel y Radilla 2012, 125-126). Por tanto, la pregunta que se plantea es: ¿Cómo enfrenta la familia la desaparición de uno de sus miembros desde el marco de la seguridad humana?

El objetivo es analizar cómo enfrenta la familia la desaparición de uno de sus miembros a través de una investigación cualitativa. La intención de este estudio es hacer visible la experiencia de familiares de víctimas de desaparición forzada desde su perfil emocional, así como determinar cómo enfrentan los familiares la pérdida del ser querido, para tomar como punto de partida al ser humano y no al Estado en las políticas de seguridad. Esta investigación ha sido realizada con 
apoyo de una organización no gubernamental, el Comité de Familiares de Personas Detenidas Desaparecidas en México ¡Alzando Voces! El muestreo fue estructural (Penalva et al. 2015, 32) por la posición que este organismo tiene como defensor de los derechos de los familiares de víctimas de desaparición forzada en México y por su origen en agosto de 2009. Las técnicas de investigación desarrolladas han sido las siguientes:

a) Entrevista de grupo semiestructurada, aplicada de forma verbal en una reunión con los familiares de personas desaparecidas forzadas de esta organización que aceptaron participar de manera anónima y confidencial. El objetivo fue conocer si sentían apoyo por parte de las instituciones estatales para enfrentar el suceso. La aplicación fue grupal y voluntaria, es decir, algunos de los integrantes del colectivo levantaron la mano e hicieron los comentarios. Con este tipo de entrevista los afectados expresaron sus puntos de vista.

b) Entrevista estandarizada abierta, se trata de una entrevista con cuestionario en la cual las respuestas son contestadas libremente y en orden secuencial por todos los entrevistados (Penalva et al. 2015, 19). Es importante mencionar que durante la reunión se expresaron los objetivos de la presente indagación, y sólo tras mostrar su aceptación procedían a participar. El objetivo fue conocer qué suceso o sucesos habían resultado más difíciles de experimentar, cómo los enfrentaron y cómo conducirían su vida después de ello.

Para el análisis de los datos recabados se realizó una descomposición de los mismos para el establecimiento de conceptos relevantes y agrupación en categorías a través de describir, clasificar y hacer conexiones. La primera tarea fue la reducción de datos y el establecimiento de categorías para después conectar los conceptos (Dey 1993, 32).

\section{Desaparición forzada en la actualidad mexicana}

Describir las desapariciones en la historia mexicana es una labor que escapa a los alcances del presente artículo, ya que el Estado ha usado la desaparición forzada como estrategia de terror en distintos periodos para lograr el proyecto de modernidad al que alude Bauman. Proyecto en el que pesa tanto la construcción de lo que se ajusta a él como la desaparición y/o domesticación de lo disfuncional, de lo 
incomodo, de lo conflictivo (Gatti 2017, 51). Lo anterior se materializa en la construcción del Estado mexicano, al justificar la seguridad estatal del enemigo (Labiano 2009).

Por tanto, más allá de encajonar la terminología jurídica alrededor de la desaparición forzada, resulta más esclarecedor describir subjetividades, características de las relaciones, la forma en que se presenta en México desde el cuadro emocional de los familiares de dichas personas. Tal cómo lo sustenta Da Silva (2001:16), es necesario "armar el rompecabezas" en torno a la desaparición forzada: "Desde las prácticas se van tramando sentidos públicos y también personales, en torno a los "desaparecidos»", sabiendo que a partir de lo ordinario de la vida de los afectados, tanto en su ámbito colectivo como íntimo, es donde se empezó a fraguar lo sucedido (la desaparición) y lo producido por eso (el desaparecido) a partir de ideas como quiebra, fractura, vacío, invisibilidad, inexistencia, ausencia, paradoja, irrepresentabilidad (Gatti 2017: 13).

El estudiar la seguridad humana de los familiares de personas desaparecidas bajo un estudio particular, cualitativo y centrado en sus propias características nos aparta de lo que refiere Elisabeth Anstett (2017: 40): "aplicar de forma desmesurada y globalizada el término desaparición forzada a todos los sucesos, conlleva negar la especificidad de los sufrimientos padecidos por los sobrevivientes, y de modo más general, por los familiares de las víctimas". Esta exportación terminológica acaba entonces descontextualizando directamente estas violencias e ignorando su caracterización sociológica. A esta tendencia globalizada de los derechos algunos autores la refieren como "forms of vernacularization", cuando se importan instituciones transnacionales a los ámbitos locales, aplicándolas como cinturones de fuerza, dejando de lado las particularidades de las identidades locales (Engle 2006, 44).

De ahí que se sugiera una "vida social de los derechos", partiendo de analizar conjuntamente las prácticas, percepciones cosmopolitas y populares de los derechos, cartografiando la diversidad de actores sociales - agente del conocimiento- que participan en las traducciones entre un ámbito y otro, en un movimiento de ida y vuelta, desde la arena global hacia abajo y desde el ámbito local hacia arriba, con un enfoque recíproco de complementariedad (Ferrándiz 2010,167).

Gatti se refiere a un concepto científico de desaparición que distingue tres tipos, entre los que está: "el desaparecido originario extendido", que es:

[...] El resultado del aterrizaje o vernacularización de lo que el derecho internacional tipifica como "desaparición forzada" en casos 
cuya empiricidad no coincide con ese tipo jurídico. Es el propio acto de nominación, más el despliegue consecuente en esos casos de la maquinaria del humanitarismo, el que arrastra estos casos en dirección al primer tipo (desaparición originaria) a la adopción de las características propias de él. Hechos como que la desaparición o el desaparecido se nombren retroactivamente, o las dificultades para ajustar lo sucedido a lo que el tipo jurídico indica, hacen [que] los de este tipo [...] estén repletos de paradojas, efervescentes, precarios y muy creativos, en los que el desembarco de la categoría y de todos los soportes institucionales, materiales, organizativos, nominales, etc., va acompañado de una intensa pugna por los sentidos de ese significante y por apropiarse de él, por ser adecuadamente víctima de desaparición forzada, por encontrar identidad con esta categoría nueva para muchos de los que se instalan en ella. (Gatti 2017, 23)

Precisamente, la exportación de la designación "desapariciones forzadas" al contexto de violencia generalizada y diseminada, desdibuja además el grado de implicación de la población en su conjunto (recordemos una evidencia: a mayor número de víctimas, mayor número de asesinos) en la práctica de las violencias y, más general, el respaldo (activo o pasivo) de que gozaron los autores de los diferentes abusos (por denuncia, aporte directo de mano de obra, omisión de intervención). Más aún, la exportación ampliada de la designación de personas desaparecidas fuera del contexto de las dictaduras de Sudamérica contribuye a reforzar aún más la confusión sobre la naturaleza de los crímenes cometidos, pues se ignora la especificidad del tratamiento post mortem de las víctimas de desapariciones forzadas, los desafíos vinculados con la confiscación y el secuestro de los cuerpos (Anstett 2017, 33).

En México se estima que hay un nuevo tipo de desapariciones forzadas: "desapariciones originarias extendidas" que comenzaron durante el gobierno de Carlos Salinas de Gortari, y persistieron a lo largo de las administraciones posteriores. El 10 de diciembre de 2006, apenas unos días después de que llegara a la presidencia, Felipe Calderón Hinojosa hizo una declaración pública de guerra contra las drogas. Dicho acto implicó una estrategia de seguridad pública consistente en la confrontación violenta en contra de los cárteles del narcotráfico, a través de operativos conjuntos en donde participaban activamente las Fuerzas Armadas Mexicanas. Los resultados de los datos que documentan crímenes graves, entre ellas la desaparición forzada de personas, son simplemente aterradores. El Registro Nacional de Personas Extraviadas o Desaparecidas (Registro oficial de las autoridades mexicanas) hasta el $1 .^{\circ}$ de enero de 2018 reporta 34.656 personas 
desaparecidas (RNPED 2018). De acuerdo con la Procuraduría General de la República (PGR), que era el órgano encargado de la persecución de los delitos en México, se reportaron un total de 732 averiguaciones previas (investigaciones) iniciadas en el fuero federal por el delito de desaparición forzada de 2006 a marzo de 2017, de las cuales, la PGR solamente judicializó 19. En total, el Poder Judicial emitió, en ese mismo periodo, 9 sentencias condenatorias sobre desaparición forzada, solo 7 de ellas por expedientes iniciados después del 2006; cifra que evidentemente no corresponde con la magnitud del fenómeno de la desaparición (Guevara y Chávez 2018, 166).

La desaparición de personas en México es una constante de vida. Sin embargo, no existen datos puntuales sobre la misma. Sales Heredia (el zar antisecuestros durante el sexenio de Peña Nieto) aceptó a principios de febrero de 2014 que por cada caso de secuestro o desaparición que se denunció en 2013, hubo 11 más por día que no fueron denunciados. Esto indica que, si en el año 2013 fueron denunciados 1.695 secuestros ante el Ministerio Público, en realidad las personas desaparecidas habrían sido 18.645, o sea, 51 desapariciones por día, más de dos desapariciones por hora (Mastrogiovanni 2017, 45).

En este escenario podemos constatar que ese proyecto de modernidad auspiciado por la idea de seguridad estatal genera la máquina aplastante de lo distinto, de lo que no sirve, y llega al extremo de no tener notas distintivas del individuo que desaparece entre ciudadano y enemigo. Así mismo, el cumplimiento "acrítico de órdenes" (Bauman 1997) por quienes aplican las medidas de seguridad genera diversas formas de desaparición.

Para Robledo $(2012,88)$ existen cinco tipos de desaparición. En todos ellos participan grupos armados, con o sin uniforme, que detienen a las personas con fines aparentemente sin sentido, pues a pesar de que solicitan rescate, nunca regresan a las víctimas. Uno de estos tipos es cuando se paga el rescate y se denomina "secuestro y levantón"; otro, cuando se pide el rescate, no se obtiene y tampoco se regresa a la víctima: "secuestro y desaparición". Uno más, cuando se detienen a las personas en sus domicilios o espacios públicos sin sostener comunicación con los familiares: "levantón y desaparición". La autora usa el término "desaparición forzada" solo para la detención donde participan elementos del Estado de forma directa y después no se sabe el paradero de los detenidos; por último, llama "desaparición simple" al sujeto que no deja rastro y tampoco hay información sobre cómo sucedieron los hechos.

Como apunta Ferrándiz $(2010,175)$, una desaparición forzada es más que un asesinato. Expresa, además, la voluntad política de 
no dejar rastro para imposibilitar el trabajo de la memoria de las generaciones futuras, convirtiendo a las víctimas en espectros. En el escenario mexicano no existe voluntad política para esclarecer las formas, los sujetos y las circunstancias bajo las cuales tienen lugar las desapariciones. El común denominador de estos hechos, que se mantuvieron durante todo el sexenio de Calderón y que se conservaron con Enrique Peña Nieto, es su aparente casualidad junto con la criminalización de las víctimas. Así lo narra el periodista Mastrogiovanni:

En el contexto actual la actitud que se hizo costumbre, es el atribuir a las nuevas víctimas de desaparición y de desaparición forzada, públicamente y a través de los medios de comunicación, la sospecha de algún tipo de culpabilidad. Junto con esto se destaca el elemento aparentemente aleatorio y "sin sentido" de las desapariciones recientes [...] así se difunde la idea, el lugar común, de que las víctimas de desaparición forzada son criminales y, por ende, se merecían lo que les pasó, es un silogismo perverso que cierra un círculo de prejuicio e impunidad. (Mastrogiovanni 2017, 35)

Una de las peculiaridades de la desaparición forzada como práctica social genocida es la invisibilidad moral del hecho y de las víctimas (Feierstein 2017, 48). Sin embargo, como lo explica Anstett $(2017,33)$, en el contexto de las masacres recurrentes perpetradas en Guatemala y México, en el marco de la Guerra Civil Española o en el periodo franquista (a las cuales se aplica desde hace un tiempo el nombre de desapariciones forzadas), se advierte por el contrario el carácter público, notorio e incluso, a veces, espectacular de los crímenes cometidos por los militares, los paramilitares, los policías o sus esbirros, que se inscribe en un registro antropológico propio de la búsqueda de trofeos.

El papel del Estado en las desapariciones a través de los cuerpos militares y policiacos se fortalece por la alianza criminal entre éstos y los narcotraficantes. Este elemento fue patente en la desaparición forzada de 43 estudiantes en Iguala, Guerrero, los días 26 y 27 de septiembre de 2014. El Grupo Interdisciplinario de Expertos Interdependientes (2015), formado por la Comisión Interamericana de Derechos Humanos, reportó una serie de anomalías en la investigación, además emitió algunas recomendaciones para el asunto en concreto y otras generales en cuanto a la desaparición forzada en México. Este proceso dejó ver de manera abierta la problemática; por ejemplo, con la tipificación del delito, los protocolos de búsqueda y localización de las personas, el resguardo de manera debida del lugar del hallazgo, 
contar con un programa nacional de exhumaciones, la ausencia de una Comisión de búsqueda para personas desaparecidas y dejar patente la nula atención a los familiares como víctimas de estos hechos.

Los expertos hablaron de un "confort investigativo", de la costumbre de basar las investigaciones exclusivamente en confesiones. El gobierno mexicano intentó encubrir los delitos cometidos por servidores públicos, militares, marinos, policías federales y demás corporaciones militarizadas, además realizó la tortura de los presuntos responsables con el ánimo de hacer cuadrar la hipótesis en torno a la verdad histórica de los hechos sustentada por él. Sin embargo, el mayor aprendizaje que se logró a partir del 26 de septiembre de 2014 es que la desaparición forzada se volvió tema central de la agenda pública, gracias a la fuerza y la decisión de los padres de los normalistas, sus compañeros, los movimientos ciudadanos y la resonancia internacional.

Por último, se puede observar un fenómeno denominado "nuevas desapariciones forzadas" consistentes en individuos que, sin causa aparente, son desaparecidos con la participación de agentes del Estado y grupos de narcotraficantes (Mastrogiovanni 2017, 35).

\section{La seguridad humana y los modelos teóricos que la intentan explicar}

Como se apuntó en líneas anteriores, en esta pesquisa se busca generar un viraje teórico en cuanto a la seguridad estatal para construir una humana. No obstante, el desarrollo de la concepción teórica de la seguridad humana es complejo debido a su contenido indeterminado, aunado al escaso interés académico, estrictamente en el ámbito jurídico, así como la ausencia de políticas y la gobernanza para promoverla en los países y en las regiones.

El uso del término "seguridad humana" surge como efecto del desenfrenado proceso de globalización y las amenazas en relación con las nuevas y viejas guerras; tiene como objeto principal que la seguridad tome un nuevo enfoque sobre la concepción única y exclusiva de la del Estado para centrarse en la vida y la dignidad humana (Ariza 2010). Después de la Guerra Fría tienen lugar otro tipo de conflictos que la doctrina cataloga como "new wars" (Kaldor 2007) y se refieren a los conflictos internos que rebasan los efectos negativos de los conflictos

2 Término que emplea Kaldor para hacer referencia a los conflictos que aparecen al concluir la Guerra Fría. 
interestatales. Así lo puso en evidencia, por ejemplo, el informe sobre Desarrollo Humano en el año 2013: "Los conflictos posteriores a la Guerra Fría han cobrado más de 5 millones de víctimas, 95\% de las cuales eran civiles" (Kaldor 2007, 70-71). Asimismo, Yaniv (2014, 104) indica que "el $70 \%$ de los conflictos armados ocurridos después de 1945 han sido internos".

Bajo este escenario para David Baldwin (1997, 13 y ss.) es crucial replantear el tema de seguridad a través de cuestionar lo siguiente:

a) ¿Para quién es la seguridad?

b) ¿Qué valores hay que asegurar o proteger?

c) ¿Qué amenazas a la seguridad se perciben?

d) ¿Con qué medios se puede garantizar la seguridad?

El eje transversal de la primera interrogante es no tener al Estado como objeto de seguridad, sino a los individuos y las colectividades, por ende, se apuesta por orientaciones micro cósmicas basadas en las necesidades y peligros en que viven las personas, lo que a su vez exige nuevas estrategias de investigación y aplicación del conocimiento para la reestructuración y creación de políticas públicas en materia de seguridad.

El Informe sobre Desarrollo Humano de 1994 sostuvo que el concepto de seguridad debe tomar una inflexión de la idea de protección armamentista de las fronteras nacionales hacia la idea de reducción de la inseguridad cotidiana de las personas (o de la inseguridad humana). Así la seguridad se concibe como una búsqueda universal por liberarnos de la necesidad y el miedo, por lo tanto, la seguridad humana surge como conditio para contar con paz, pero para tal cometido es pertinente girar la visión de políticas públicas actuales que versan sobre evitar y abatir conflictos a la implementación de políticas generadoras de cultura de paz y bienestar (Programa de Naciones Unidas para el Desarrollo 1994).

Asimismo, dicho informe determinó que son siete las áreas que constituyen a la seguridad humana:

1. Seguridad económica: ingreso básico asegurado.

2. Seguridad alimentaria: acceso físico y económico a los alimentos que se compran.

3. Seguridad en materia de salud: acceso amplio y garantizado a un servicio de salud.

4. Seguridad ambiental: acceso a un medio ambiente físico saludable y servicios de saneamiento.

5. Seguridad personal: garantía de la integridad física. 
6. Seguridad de la comunidad: garantía de libertad política, ideológica, cultural, generacional o étnica.

7. Seguridad política: garantía de los derechos humanos y fundamentales dentro de un Estado democrático (Programa de Naciones Unidas para el Desarrollo 1994, 27).

Tal parece que hay un consenso en relación a girar la concepción estado-céntrica de la seguridad por una noción humano-céntrica. Sin embargo, el debate teórico sigue abierto en cuanto al contenido de la seguridad humana; es decir, sobre qué valores hay que proteger o qué amenazas asechan a los seres humanos, además de establecer los medios para garantizarla. Hasta el momento se detectan tres posturas teóricas diferentes:

a) La seguridad humana y el desarrollo humano.

b) La seguridad humana y la liberación del miedo.

c) La seguridad humana y los derechos humanos (dignidad humana).

En la primera postura los autores se inclinan por entender la seguridad humana como la garantía del ejercicio adecuado de los derechos económicos, sociales y culturales; es decir, potenciar el Desarrollo Humano entendido como un proceso de dos caras. Una de ellas es la formación de las capacidades humanas, tales como mejoramiento de la salud, el conocimiento y las habilidades. Y, la otra cara, sería el uso que hacen las personas de las capacidades que han adquirido para el ocio, para propósitos productivos o como seres activos en asuntos culturales, sociales, históricos y políticos (Ryerson y Amitav 2008). Esta postura teórica considera, desde un sentido amplio a la seguridad humana, como un estar libre de necesidad; esto es, proporcionar al individuo libertad frente a las necesidades tales como el hambre o la enfermedad "freedom from want" (Pérez de Armiño 2007).

Amartya Sen (2000) afirma que la seguridad humana debe apuntalar el desarrollo de las personas y las comunidades. Esta idea es seguida por la Comisión de Seguridad Humana creada por el gobierno japonés en 2001. En el año 2003 la Comisión definió el propósito de la seguridad humana en los siguientes términos:

[...] Consiste en proteger la esencia vital de todas las vidas humanas de una forma que realce las libertades humanas y la plena realización del ser humano. Seguridad humana significa proteger las libertades fundamentales: libertades que constituyen la esencia de la vida. Significa proteger al ser humano contra las situaciones y las 
amenazas críticas (graves) y omnipresentes (generalizadas). Significa utilizar procesos que se basan en la fortaleza y las aspiraciones del ser humano. Significa la creación de sistemas políticos, sociales, medioambientales, económicos, militares y culturales que, en su conjunto, brinden al ser humano las piedras angulares de la supervivencia, los medios de vida y la dignidad. (Comisión de la Seguridad Humana 2003, 3)

Esta línea teórica es criticada en virtud de su exagerada amplitud. Daniel $\mathrm{H}$. Deudney lo expone en los siguientes términos: "si todo lo que causa una reducción del bienestar humano es catalogado como una amenaza a la seguridad, el término pierde toda utilidad analítica para convertirse en un simple sinónimo de malo" (Deudney 1999, 187219). Contradiciendo este argumento, el problema es precisamente no mirar de forma integral y holística la generación de los conflictos que provienen de la falta de bienestar al interior de los Estados; por consecuencia, resulta necesario ir hacia nuevos derroteros en materia de seguridad.

La segunda posición teórica define a la seguridad humana como el derecho de las personas, las sociedades y los países, de vivir seguros y de prosperar en paz (Instituto Latinoamericano de las Naciones Unidas para la Prevención del Delito y el Tratamiento del Delincuente 2011). Esta postura comenzó a desarrollarse con el objetivo de aminorar los impactos negativos de las new wars al interior y exterior de los Estados. Propugna por atender los miedos y las inseguridades de las personas y las comunidades de acuerdo al tipo de conflicto que padezcan, dejando de lado la protección de la nación. Desde la perspectiva de Owen y Liotta $(2006,47)$, la seguridad humana debe atenderse desde las circunstancias históricas de cada país; esto es, diseñar un sistema de umbrales mínimos que establezcan las áreas prioritarias (militar, alimentaria, salud, etc.) de acuerdo al tipo de conflicto.

Esta visión teórica se considera restringida, ya que su propósito es liberar a los individuos del miedo (freedom from fear) ante situaciones que, como los conflictos armados, ponen en peligro sus vidas y su seguridad personal. En términos puntuales la seguridad humana "es estar libre de miedo por conducto de atacar las amenazas y producir una mayor resistencia ante ellas" (Sen 2000, 6). El gobierno de Canadá y Noruega en 1998 impulsaron la Red de Seguridad Humana bajo esta idea teórica. Esta orientación es criticada porque, según autores, "no es capaz de captar el carácter complejo, sistémico y multidimensional de las realidades, ni de proponer un paradigma de auténtica seguridad para las personas que las sufren, que incluso despoja a ese paradigma 
del potencial transformador" (Pérez de Armiño 2007, 76). No obstante, este enfoque hace hincapié en los estragos que producen los conflictos armados y en atender umbrales mínimos de satisfacción, es decir, avanza en la operatividad de la seguridad humana.

La última perspectiva liga a la seguridad humana con los derechos humanos, consistente en proteger la esencia vital de todas las vidas humanas. Bajo esta concepción la seguridad humana está unida con la dignidad o con el derecho de no ser humillado, lo que conlleva el problema de determinar los indicadores de dignidad humana relacionados con la seguridad o lo que significa no ser objeto de humillación ${ }^{3}$. El término humillar encarna la idea de no herir el amor propio o la dignidad de alguien. En este sentido, la seguridad humana sería el derecho a no ser humillado por características físicas, emocionales y mentales. Sería atacar las acciones y omisiones que solapan condiciones indignas para el ser humano (Sen 2000).

Desde este enfoque hay quien considera a la seguridad humana como:

Un nuevo principio fundamental, de carácter programático y de alcance horizontal, que impone a los Estados el deber de cooperar en su garantía y requiere el refuerzo (y, en algunos casos, la redefinición) de aquellos instrumentos y capacidades que se consideren necesarios para proteger el derecho de los individuos a que su supervivencia y dignidad como seres humanos no sean expuestas a daño, riesgo o peligro. (Pérez 2012, 171)

Esta teoría une a la seguridad humana con los derechos humanos. No obstante, el desarrollo de esta postura es incipiente, debido a que no especifica si todos los derechos humanos están dentro del contenido de la seguridad humana, así como qué parámetros se incluyen para fijar la seguridad humana a partir de defender la dignidad. Además, Yaniv $(2014,104)$ plantea una pregunta atinada: "¿La seguridad humana genera nuevos derechos humanos o promueve y mejora los derechos humanos ya existentes?". Para este autor existe una relación indisoluble entre los derechos humanos y la seguridad humana, además considera que el no garantizar los derechos humanos constituye una amenaza para la seguridad humana.

3 El término dignidad es amplio y está lleno de significados de acuerdo a la doctrina que se use para dotarlo de contenido: religiosa, jurídica, etcétera. Para los propósitos de este estudio los autores que ligan a la seguridad humana y la dignidad, lo hacen como se explica en este apartado. 
Desde el enfoque epistemológico de este trabajo se considera que esta última perspectiva es la más sólida, ya que subraya la importancia de garantizar los derechos humanos como contenido principal de la seguridad humana, sin limitarse a la protección los derechos económicos, sociales y culturales o al miedo. Así la seguridad humana es definida como un principio fundamental para el Estado y la comunidad internacional, que consiste en garantizar la plena realización de los derechos humanos, sobre todo cuando las personas están inmersas en un conflicto. Por tanto, la seguridad humana se diagnosticará a partir de las circunstancias históricas, sociopolíticas de cada país, para así ubicar los umbrales mínimos o prioritarios que se deben proteger (Ariza 2010). Bajo esta visión, la seguridad estatal no tiene que alegarse como argumento para vulnerar los derechos humanos de los habitantes, ni justificar las intervenciones militares; sólo sería válida dicha intervención cuando tenga el objetivo de coadyuvar con la garantía de los derechos humanos de los habitantes en ese país.

El contenido de la seguridad humana a partir de la garantía efectiva de los derechos humanos es una concepción idónea para un contexto como el latinoamericano, donde proliferan los enemigos que el Estado diseña por no ajustarse al proceso civilizatorio. Asimismo, están mermadas las condiciones de vida dignas para las personas, ya que "es una región desigual en aspectos como el desarrollo social, el desarrollo medio ambiental, el acceso a la cultura, las libertades, etc." (Kliksberg 2005, 411). Según datos que reporta la Organización de Estados Americanos, algunos de los países en América Latina y el Caribe ostentan las más altas tasas de homicidio del mundo. En la región sólo habita el $8 \%$ de la población mundial, pero se materializa el $42 \%$ de todos los homicidios por arma de fuego y el $66 \%$ de todos los secuestros del planeta (OEA 2008). La Comisión Económica para América Latina y el Caribe reportó que, en el año 2014, el $28.5 \%$ de la población de la región se encontraba en situación de pobreza (168 millones de personas), porcentaje que aumentó a $29.8 \%$ en 2015 (178 millones) y a 30.7\% en 2016 (186 millones de personas). La pobreza extrema pasó del $8.2 \%$ en 2014 (48 millones de personas) al 10\% en 2016 (61 millones de personas). En este tenor, la política de seguridad requiere atender de forma contextualizada los problemas que padece nuestra población y generar una inflexión sobre la concepción estatal para construir una seguridad para los latinoamericanos (CEPAL 2017).

El desarrollo teórico de la seguridad humana y su garantía están sujetas a serios desafíos, empero, el primer paso consiste precisamente en superar la concepción única y exclusiva de la seguridad del Estado 
para trabajar en una seguridad al interior del mismo que se centre en potencializar la vida y la dignidad humana. En consecuencia, la planeación debe estar estructurada para detectar las amenazas a los derechos humanos de las personas y las comunidades desde el marco estatal y no para el Estado. Además, resulta crucial plantearnos un enfoque de la seguridad humana desde y para los latinoamericanos y, por supuesto, para México.

\section{La seguridad emocional: parte del núcleo de la seguridad humana}

Al referirnos a la seguridad humana como una construcción desde y para México significa determinarla a partir de los mexicanos, sumergidos en sus pensamientos, emociones y en su ambiente cultural-social. Es decir, fincar la seguridad a partir de las prácticas que impulsan los deseos y las necesidades de la gente y las prácticas que les impiden alcanzar esos objetivos; sólo así se podrá catalogar a la seguridad como humana. A esta postura algunos autores la llaman una teoría impura, porque se traduce en una comprensión contextual de las prácticas individuales-sociales (Illouz 2007, 201). Ortega y Gasset $(1966,375)$ sostiene que: "El hombre se va haciendo en la serie dialéctica de sus experiencias, por tanto, en vez de «naturaleza» el hombre tiene historia". Por ende, desde la perspectiva teórica de esta investigación, la seguridad humana se perfila a la protección de los seres humanos sumergidos en su ambiente cultural-social; a partir de ahí, se determinan las estrategias para proveerlos de seguridad. Desde este eje, partimos de considerar que la esfera emocional constituye un fundamento antropológico de la seguridad humana por ser parte del núcleo vital de las personas. El marco teórico que ocupamos es analizar las emociones como elementos socioculturales; desde los planteamientos de Martin-Baró $(1985,93-109)$ se intenta plantear el proceso psicosocial a partir de la expresión de las emociones de las personas que viven el conflicto, significa rescatar la experiencia original de los grupos y personas y devolvérselas en dato objetivo, lo que permite formalizar la conciencia de su propia realidad verificando la validez del conocimiento adquirido. Desde este enfoque la seguridad humana es para los seres humanos y no para defender al Estado de sus enemigos; conlleva centrarse en las emociones, pensamientos y acciones de los individuos dentro de un contexto social.

Para autores como McCarthy (1994), Illouz (2007) o Le Breton (2012), las emociones, lejos de ser pre sociales o pre culturales, son 
significados culturales y relaciones sociales fusionadas de manera inseparable, y esa fusión le confiere la capacidad de impartir energía a la acción. Lo que hace que la emoción tenga esa energía es el hecho de que siempre concierne al yo y a la relación del yo con otros situados culturalmente. Ya que, sin duda, la emoción es un elemento psicológico, pero es en mayor medida un elemento cultural y social; por medio de la emoción representamos las definiciones culturales de personalidad, tal como se las expresa en relaciones concretas e inmediatas, pero siempre definidas en términos culturales y sociales (Illouz 2007, 15 y 16). Le Breton afirma que "las emociones son modos de afiliación a una comunidad social, una forma de reconocerse y de poder comunicar juntos, bajo un fondo emocional próximo. Por tanto, la emoción es una relación, no es una naturaleza descriptible sin contexto ni independiente del actor" (Le Breton 2012, 74-75).

Desde esta tesis, las emociones no pueden ser divorciadas de los significados socioculturales en los que tienen experiencia y son expresadas. La sociología de las emociones implica cómo las emociones se diferencian, socializan y administran socialmente. Catherine Lutz argumenta que la experiencia emocional "no es pre cultural sino preeminentemente cultural" (Lutz 1988, 5). Los estudios de las emociones en el plano social demuestran que el yo y su identidad son dialécticas que se construyen en la práctica. De tal forma que, las prácticas sociales son quienes mueven al sujeto a promover su identidad. Esta autora critica que las emociones sean descritas de forma académica a través de ideas que están fuera de la experiencia social.

Para McCarthy las emociones positivas o negativas son una dialéctica construida por el yo con otros, yo en un ambiente social determinado:

La teoría de la cultura invita a identificar los amarres institucionales y discursivos de las emociones; es decir, explicar el contexto social mediante el cual el yo se experimenta como realmente es, como colectivamente se piensa, ya que la cultura es el ensamblaje de esos discursos dentro de las cuales las emociones llegan a ser. (McCarthy 1994, 279)

Desde hace algunos años diversos investigadores estudian el trauma desde una visión psicosocial (Martín-Baró 1990, Madariaga 2002), cuyos planteamientos los han llevado a considerar que cuando se está inmerso en condiciones sociales de conflicto o amenaza, ello conlleva experimentar emociones y traumas psicosociales que sugieren la existencia de dos condiciones: 
a) Que la herida que afecta a las personas ha sido producida socialmente, es decir, que sus raíces no se encuentran en el individuo, sino en su sociedad.

b) Que su misma naturaleza se alimenta y mantiene en la relación entre el individuo y la sociedad, a través de diversas mediaciones institucionales, grupales e incluso individuales. Lo cual tiene obvias e importantes consecuencias a la hora de determinar qué debe hacerse para superar estos traumas (Martín-Baró 1990, 10).

Para Madariaga $(2002,17)$ el psiquismo individual y social está representado en sus perturbaciones, un fenómeno que no nace de la interioridad de los procesos mentales ni de conflictos intersubjetivos inmediatos, sino refleja los acontecimientos políticos que se desarrollan fuera del individuo, en el contexto social. El punto de arranque del trauma está en la sociedad misma, en la forma como las clases y grupos sociales dirimen sus conflictos por el poder político. Siguiendo este argumento, la tesis médica sobre el trauma que privilegia una visión orgánica-individualista, desde el perfil psicosocial es incompleta porque dibujan a individuos asociales, que viven el drama en una suerte de soledad autista de su campo intrapsíquico. Con este matiz conceptual Martín-Baró $(1990,35)$ alude a dos aspectos que parecen esenciales para una adecuada comprensión de la realidad del trauma psíquico-social:

a) El trauma tiene un carácter dialéctico: la naturaleza del trauma hay que ubicarla en la particular relación social de la que el individuo sólo es una parte. No puede predecirse sin más que un tipo de situación social vaya a generar mecánicamente un trauma a cualquier persona, o que un determinado tipo de persona nunca sufrirá un trauma. Se afirma su carácter histórico.

b) Las relaciones sociales: su mantenimiento es el que alimenta y multiplica los casos de individuos traumatizados.

El trauma psicosocial constituye así la cristalización concreta en los individuos de unas relaciones sociales aberrantes y deshumanizadoras, como las que prevalecen en situaciones de guerra civil. Esto significa que la cadena tiende a romperse por el eslabón más débil: los sectores sociales más desprotegidos y los sectores sociales más directamente alcanzados por el conflicto y la actividad bélica (Martín-Baró 1990, 35).

Para Lira y Castillo (1993) lo traumático en la realidad social se manifiesta con cierta regularidad cuando los hechos sobrepasan la 
capacidad y los recursos de los grupos sociales, o de las personas involucradas. Como lo sostiene Madariaga $(2002,17)$, se trata de grupos o colectivos humanos en los que es posible reconocer puentes interconectores entre sus propias vivencias. Cada sujeto elabora — de modo peculiar, pero siempre socialmente- la experiencia traumática al interior de sus contextos resocializadores (familia, comunidad, organizaciones sociales, partidos políticos, etcétera), ya sea consciente o inconscientemente, produciendo asignaciones de casualidades, cosmovisiones, pautas sociales de conducta, explicaciones políticoideológicas, entre otras, que definen ciertas formas de conducta social.

Así que vale la pena analizar las pautas de conducta social que tenemos los mexicanos ante la guerra contra el narcotráfico, desapariciones forzadas, tortura, pobreza; cómo hemos elaborado de manera psicosocial estos conflictos. Es indispensable una mirada crítica a los estudios que, a través de los test basados en la psicología clínica, desean mostrar la enfermedad de las personas en contextos de conflicto de forma aislada. Estaremos en posibilidad de construir una seguridad humana si proviene de atender las pautas individualessociales de las personas sujetas a condiciones de vulnerabilidad.

Si la seguridad humana se centra en el ser humano, es crucial incluir las emociones, prácticas, la relación del yo dentro de su contexto sociocultural para conocer los aspectos que le están impidiendo vivir seguro y prosperar en paz. El objetivo principal de este estudio es rescatar la experiencia original de los grupos y personas que han padecido la desaparición de un familiar, lo que permitió analizar la forma en cómo las familias enfrentan dicho acontecimiento.

\section{Posible construcción de la seguridad humana de los familiares de personas desaparecidas forzadas: exposición de datos y análisis de resultados}

Se escuchó a las personas que informaron tener a un familiar desaparecido, sobre todo en el aspecto de si se sienten apoyados por el Estado para atender su situación. Para ello se utilizó la técnica de investigación consistente en una entrevista grupal-semiestructurada, realizada el $1 .^{\circ}$ de julio del 2014, donde participaron 10 familiares (mayores de edad), siete mujeres y tres varones que viven en distintos municipios del Estado de Michoacán. Dos personas reportaron que su padre fue quien desapareció, por lo que tuvieron que ser partícipes de la economía del hogar. De las siete mujeres, dos se convirtieron en jefas 
de familia, pues los desaparecidos fueron sus esposos. Cinco sufrieron la desaparición de un hijo, de tal manera que sienten que descuidan a sus otros hijos por buscar al que les hace falta. Sólo uno menciona que su hermano fue quien desapareció.

La visión compartida por ellos es que no hay atención a las víctimas, que las instituciones no distinguen la problemática de la desaparición forzada de los levantones y secuestros. Lo que afirma la aplicación de desaparición forzada a nuevos fenómenos que no necesariamente responden al concepto de desaparición forzada originaria. Asimismo, los datos recogidos indican no tener notas distintivas de las personas que desaparecen. Por tanto, hay diversas formas de desaparecer a un individuo en México y no existen datos oficiales confiables. Así lo mencionaron: "En Michoacán sólo un 10\% denuncia la desaparición de un familiar".

Otros datos relevantes son, que se sienten estigmatizados por la sociedad, ya que la víctima se criminaliza. Un padre en específico mencionó: "consideré dejar de buscar a mi hijo porque la policía me aseguró que mi hijo pertenecía a un grupo criminal". En este tenor, lo apuntado por Mastrogiovanni $(2017,35)$ en cuanto a la idea y el lugar común en que las víctimas de desaparición forzada son criminales y, por ende, se merecían lo que les pasó, es confirmado por los familiares. De esta entrevista se desprende que no hay causas aparentes de las desapariciones reportadas por los familiares, lo que se convierte en un lugar incierto, ya que no hay una causa común.

De una segunda entrevista, realizada el 10 de mayo del 2015, a nueve personas, a través de un cuestionario (después de una marcha masiva hacia el Palacio de Gobierno en la ciudad de Morelia) se constató: por un lado, que la mayoría de los participantes catalogaron la desaparición de su familiar como uno de los eventos más difíciles en su vida. Además, se percibió que lo que une al grupo es la identificación por el dolor de este hecho, pero también muestran cierto grado de optimismo y esperanza, lo que los mantiene unidos: "que la catástrofe se institucionalizó para ellos como un lugar estable y habitable" (Gatti 2011,180).

Por otro lado, los participantes refieren que, debido a esta situación, han sido afectados mental y psicológicamente, pues el evento ha modificado su vida. En este sentido, la situación que los perjudica no proviene de su interior, sino de una situación externa a ellos. Todos los participantes refieren que el suceso más difícil que experimentaron en su vida es la desaparición del familiar, producto de los acontecimientos políticos que se desarrollan fuera del individuo, en el contexto social (Madariaga 2002, 17). 
Como sostiene Madariaga $(2002,17)$, cada sujeto elabora - de modo peculiar, pero siempre socialmente- la experiencia al interior de sus contextos resocializadores (familia, comunidad, organizaciones sociales, partidos políticos, etcétera), ya sea consciente o inconscientemente, produciendo ciertas formas de conducta social. Cabe destacar que todos los participantes mencionan que han aprendido algo positivo de la experiencia y, a pesar de su situación, muestran interés por otros.

Es evidente que cada participante reacciona con diferentes conductas y emociones ante esta situación, pero la mayoría busca una red de apoyo para enfrentar la adversidad. La pauta social en este colectivo, a partir de la experiencia, no es negativa, ya que afianzan su interés por personas que atraviesan por la misma situación; asimismo, buscan fortalecer sus redes de apoyo familiar y de amistad. Es importante señalar cómo se reconstruye la identidad a través de prodigiosas invenciones sociales. Con esta catástrofe descubrimos la arbitrariedad de las cosas y de las identidades; también la necesidad de reinventarlas, [...] al final la identidad es un otorgamiento de significados (Gatti 2011, 173).

En cuanto a la visión de futuro, la mayoría considera la posibilidad de vislumbrar cierto grado de optimismo y esperanza a pesar de la situación adversa. Los participantes manifestaron conducir su vida hacia la solución del problema de la desaparición, a la verdad, una revolución social a encontrar a sus familiares, a buscar un gobierno que apoye la justicia y venza la maldad. La pauta social que se observa es de esperanza hacia un futuro prometedor, a clarificar su pasado, solucionarlo y enfrentarlo para avanzar al futuro.

\section{Conclusiones}

Si bien, estos datos resultan relevantes como una importante aproximación al análisis de la desaparición forzada de las personas y sus efectos en las familias, este estudio requiere profundizar aún más sobre la necesidad de generar un Estado de Derecho, para lo cual se requiere dar un giro a la política en materia de seguridad estatal, para trazar una seguridad basada en los individuos y colectividades a través de estudios profundos de sus necesidades, capacidades y emociones. Sólo así podremos transitar a políticas de seguridad eficientes. En este caso, la seguridad humana apunta a erradicar las políticas que provocan la desaparición de los individuos. Enfocar dichas políticas a conocer la verdad de lo ocurrido, a reforzar las redes de apoyo al 
interior de las familias, así como al logro de un acercamiento de las instituciones estatales, competentes, con los Comités de familiares. Este acercamiento permitiría diseñar y ejecutar acciones para la búsqueda de las personas desaparecidas y, sobre todo, medidas de reparación eficientes.

\section{Referencias}

Anstett, Élisabeth. 2017. "Comparación no es razón: A propósito de la exportación de las nociones de desaparición forzada y detenidosdesaparecidos". En Desapariciones. Usos locales, circulaciones globales, coordinado por Gabriel Gatti, 28-44. Bogotá: Siglo del Hombre Editores, Universidad de los Andes.

Ariza, Natalia. 2010. "La aplicabilidad del concepto de seguridad humana en América Latina y el Caribe: el desarrollo humano como fuente de seguridad", Oasis 15: 1-20. Acceso el 31/10/2019.https://www.redalyc. org/pdf/531/53121459003.pdf

Baena, Guillermina. 2006. Seguridad humana y capital emocional, México, D.F: UNAM.

Baldwin, David. 1997. "The concept of security". Review of International Studies 23: 5-26.

Bauman, Zygmunt. 1997. Modernidad y holocausto. Madrid: Sequitur.

Booth. Ken. 2013. "Seguridad y emancipación". Relaciones Internacionales 23: 99-116.

Bourdieu, Pierre; Chamboredon, Jean-Claude y Passeron-Jean-Claude. 2002. El oficio de sociólogo. Buenos Aires: Siglo XXI Editores Argentina.

Comisión de la Seguridad Humana (2003). La seguridad humana ahora. Nueva York: Organización de Naciones Unidas.

Comisión Económica para América Latina y el Caribe (CEPAL). 2017. Panorama social de América Latina. Santiago de Chile: Organización de Naciones Unidas. Acceso 22/11/2018. https://repositorio.cepal.org/bitstream/ handle/11362/42716/7/S1800002_es.pdf

Da Silva, Ludmila. 2001. No habrá flores en la tumba del pasado. La experiencia de reconstrucción del mundo de los familiares de desaparecidos. La Plata: Al margen.

Deudney, Daniel. 1999. "Environmental security: A critique". En Contested Grounds: Security and Conflict in the New Environmental Politics, editado por Daniel Deudney y Richard Matthew, 187-219. Albany: State University of New York Press.

Dey, Ian. 1993. Qualitative data analysis. Londres: Routledge.

Engle, Sally. 2006. "Transnational human rights and local activism: Mapping the middle". American Anthropologist, 108(1): 38-51.

Feierstein, Daniel. 2017. "Genocidio y desaparición: Los distintos usos de una práctica social en el contexto de una tecnología de poder". En 
Desapariciones. Usos locales, circulaciones globales, coordinado por Gabriel Gatti, 45-60. Bogotá: Siglo del Hombre Editores, Universidad de los Andes.

Ferrajoli, Luigi. 2010. Garantismo y Derecho Penal. México, D.F.: Ubijus.

Ferrándiz, Francisco. 2010. "De las fosas comunes a los derechos humanos: El descubrimiento de las desapariciones forzadas en la España contemporánea". Revista de Antropología Social, 19: 161-189.

Gatti, Gabriel. 2011. Identidades desaparecidas. Peleas por el sentido en los mundos de la desaparición forzada. Argentina: Eduntref.

Gatti, Gabriel. 2017. "Prolegomeno. Por un concepto científico de desaparición". En Desapariciones. Usos locales, circulaciones globales, coordinado por Gabriel Gatti: 11-27. Bogotá: Siglo del Hombre Editores, Universidad de los Andes.

Grupo Interdisciplinario de Expertos Independientes (GIEI). 2015. Primer informe del caso Ayotzinapa. Acceso 22/11/2018. https://drive.google. com/file/d/OB1ChdondilaHNzFHaEs3azQ4Tm8/view

Guevara, José A. y Chávez, Guadalupe. 2018. "La impunidad en el contexto de la desaparición forzada en México", Eunomía, 14: 162-174.

Günther, Jakobs. 2003. Derecho penal del enemigo. Madrid: Civitas.

Illouz. Eva. 2007. Intimidades congeladas. Buenos Aires: Katz discusiones.

Instituto Latinoamericano de las Naciones Unidas para la Prevención del Delito y el Tratamiento del Delincuente (ILANUD). 2011. Seguridad humana. Acceso 31/10/2019. http://www.ilanud.or.cr/A090.pdf

Jellinek, Georg. 1911. Teoría del Estado. México, D.F.: Fondo de Cultura Económica.

Kaldor, Mary. 2007. Human Security. Reflections on globalization and intervention. Cambridge: Polity.

Kant, Inmanuel. 2003. La paz perpetua. Madrid: Biblioteca virtual Miguel de Cervantes.

Kliksberg, Bernardo. 2005. "América Latina: La región más desigual de todas", Revista de Ciencias Sociales XI(3): 411- 421. Acceso el 31/10/2019. http:// www. redalyc.org/articulo.oa?id=28011302

Labiano, Virginia. 2009. La militarización de la seguridad pública en México y sus consecuencias (2000-2009). Tesis de Licenciada en Relaciones Internacionales-Universidad Nacional del Centro de la Provincia de Buenos Aires. Acceso el 31/10/2019. https://www.researchgate.net/ publication/303520372_La_militarizacion_de_la_seguridad_publica_en_ Mexico_y_sus_consecuencias_2000-2009

Le Breton, David. 2012. "Por una antropología de las emociones". Revista Latinoamericana de Estudios sobre Cuerpos, Emociones y Sociedad 4(10): 69-79. Acceso el 31/10/2019. http://www.relaces.com.ar/index.php/ relaces/article/view/208

Lira, Elizabeth y Castillo, María I. (1993). "Trauma político y memoria social". Psicología Política, 6: 95-116.

Loewenstein, Karl. 2018. Teoría de la Constitución, Barcelona: Ariel. 
Lutz, Catherine.1988. Unnatural Emotions. Chicago: University of Chicago Press.

Madariaga. Carlos. 2002. "Trauma Psicosocial, trastorno de estrés postraumático y tortura". Colección del Centro de Salud Mental y Derechos Humanos (CINTRAS). Acceso 22/11/2018 http://www.cintras. org/textos/monografias/monog_trauma_psicosocial_espanol.pdf

Martín-Baró, Ignacio. 1985. "El papel del psicólogo en el contexto centroamericano". Boletín de Psicología 17: 99-112. Acceso el 30/09/2018. http://www.facso.uchile.cl/psicologia/epe/_documentos/ getep/martin_baro_psicologia_liberacion.pdf

Martín-Baró, Ignacio.1990. Psicología social de la guerra: trauma y terapia. San Salvador: UCA editores.

Mastrogiovanni, Federico. 2017. Vivos ni muertos. La desaparición forzada en México como estrategia de terror. México D.F.: Debolsillo.

McCarthy. Ed. 1994. "The social construction of emotions: new directions from culture theory". Social Perspectives on Emotion, 2: 267-279.

Organización de Estados Americanos (OEA). 2008. La seguridad pública en las Américas: retos y oportunidades, Washington: OEA. Acceso el 31/10/2019. https://www.oas.org/dsp/documentos/observatorio/final.pdf

Ortega y Gasset, José. 1966. Obras completas. Madrid: Taurus y Fundación Ortega y Gasset.

Owen, Taylor y Liotta, Peter. 2006. "Why Human Security?". The Whitehead Journal of Diplomacy and International Relations, 1: 37-54. Acceso el 31/10/2019. http://www.taylorowen.com/Articles/Owen\%20and\%20 Liotta\%20-\%20Why\%20Human\%20Security.pdf

Penalva Clemente et. al. 2015. La investigación cualitativa: Técnicas de investigación con atlas ti. Cuenca: YDLOS.

Pérez, Carmen. 2012. "Seguridad Humana". Eunomía. Revista en Cultura de la Legalidad, 3: 167-173. Acceso el 31/10/2019. https://e-revistas.uc3m.es/ index.php/EUNOM/article/view/2128/1059

Pérez de Armiño, Karlos. 2007. "El concepto y el uso de la seguridad humana: análisis crítico de sus potencialidades y riesgos". Revista CIDOB d'Afers Internacionals, 76: 59-77. Acceso el 31/10/2019. https://www.raco.cat/ index.php/RevistaCIDOB/article/view/55707/64993

Programa de Naciones Unidas para el Desarrollo. 1994. Informe sobre Desarrollo Humano de 1994. México, D.F.: Fondo de Cultura Económica.

Rangel, Claudia y Radilla, Andrea. 2012. Desaparición forzada y terrorismo de Estado en México. México, D.F.: Plaza y Valdés, AFADEM.

Registro Nacional de Personas Extraviadas o Desaparecidas (RNPED). 2018. México, D.F.: Gobierno de México. Acceso el 31/10/2019. https://www. gob.mx/sesnsp/acciones-y-programas/registro-nacional-de-datos-depersonas-extraviadas-o-desaparecidas-rnped

Robledo, Carolina. 2012. Drama social y política del duelo de los familiares de desaparecidos en Tijuana en el marco de la guerra contra el narcotráfico. Tesis Doctoral. México, D.F.: Colegio de México. 
Ryerson Christie y Amitav, Acharya. 2008. "Human security research: progress, limitations and new directions". Working Paper. Centre for Governance and International Affairs. 11-08: 1- 29. Bristol: University of Bristol.

Sen, Amartya. 2000. "Why Human Security", International Symposium on Human Security. Tokyo, 28 July.

Smend, Rudolf (1985). Constitución y Derecho Constitucional, Madrid: Centro de Estudio Constitucionales.

Yaniv, Roznai. 2014. "The Insecurity of Human Security". Wisconsin International Law Journal 32(1): 95-141. Acceso el 31/10/2019. https:// hosted.law.wisc.edu/wordpress/wilj/files/2015/03/Roznai_final.pdf 


\section{Copyright}

Deusto Journal of Human Rights / Revista Deusto de Derechos Humanos is an Open Access journal; which means that it is free for full and immediate access, reading, search, download, distribution, and reuse in any medium only for non-commercial purposes and in accordance with any applicable copyright legislation, without prior permission from the copyright holder (University of Deusto) or the author; provided the original work and publication source are properly cited (Issue number, year, pages and DOI if applicable) and any changes to the original are clearly indicated. Any other use of its content in any medium or format, now known or developed in the future, requires prior written permission of the copyright holder.

\section{Derechos de autoría}

Deusto Journal of Human Rights / Revista Deusto de Derechos Humanos es una revista de Acceso Abierto; lo que significa que es de libre acceso en su integridad inmediatamente después de la publicación de cada número. Se permite su lectura, la búsqueda, descarga, distribución y reutilización en cualquier tipo de soporte sólo para fines no comerciales y según lo previsto por la ley; sin la previa autorización de la Editorial (Universidad de Deusto) o la persona autora, siempre que la obra original sea debidamente citada (número, año, páginas y DOI si procede) y cualquier cambio en el original esté claramente indicado. Cualquier otro uso de su contenido en cualquier medio o formato, ahora conocido o desarrollado en el futuro, requiere el permiso previo por escrito de la persona titular de los derechos de autoría. 